\title{
A fuzzy method for the selection of customized equipment suppliers in the public sector
}

\author{
Antonio Rodríguez * \\ Universidad Alfonso X El Sabio, Madrid, Spain
}

Received: October 27, 2014

Accepted: December 23, 2014 Online Published: January 15, 2015

DOI: $10.5430 /$ air.v4n1p36

URL: http://dx.doi.org/10.5430/air.v4n1p36

\begin{abstract}
The acquisition of customized equipment usually requires the selection of a technology supplier to accomplish a development project. This requires the evaluation of the suppliers' proposals that may be assessed by different evaluators in different ways (single numerical values, intervals or linguistic values). In the public sector, this process may require the prior publication of the scoring rules in a request for proposal (RFP). This may force the evaluators to assign weights in advance to characteristics whose technical significance is known but whose significance for the evaluation is unknown. An inappropriate assignation of weights in the evaluation may lead to wrong conclusions. The objectives of the research were the implementation of a method for the evaluation of offers, including the adaption of weights as part of the evaluation process without violating the principles of transparency and non-discrimination that are generally required by the legislation; the integration of quantitative and qualitative criteria in a flexible procedure; and the verification for possible rank reversals. This paper proposes the use of trapezoidal fuzzy numbers (TFN) for the simultaneous implementation of different types of evaluations, incorporates variable weights analysis (VWA) for the subsequent adjustment of weights, and proposes a simple method for the detection of rank reversal. A numerical example is presented using data from an actual case.
\end{abstract}

Key Words: Project selection, Supplier evaluation, Trapezoidal fuzzy numbers, Variable weights analysis, Rank reversal

\section{Introduction}

The acquisition of customized equipment usually requires the implementation of a project management approach and a tendering process for the selection of a technology supplier. This process includes the issue of a request for proposal (RFP) where the customer specifies the requisites for the suppliers to participate in the tendering process including those technical specifications whose fulfilment is considered mandatory.

Upon the reception of the proposals, those that do not fulfill all of the mandatory requirements are directly discarded. The remaining offers are evaluated according to varied eval- uation criteria. The screening process of the submitted offers is a case of supplier evaluation and selection, which falls within the scope of multi-criteria decision analysis.

Most of the evaluation criteria correspond to technical specifications that can be expressed through numerical values. In some cases, the implementation of a procedure for quantitative evaluation and the automatic application of formulas reinforce transparency and prevent the subjectivity in the evaluation process. Several formulas have been proposed where weights are associated to evaluation criteria in accordance to their assigned importance.

Nevertheless, qualitative aspects cannot be evaluated by the

* Correspondence: Antonio Rodríguez; Email: anrodrsua@gmail.com; Address: Departamento de Ingenierías TIC, Escuela Politécnica Superior, Universidad Alfonso X El Sabio, Villanueva de La Cañada, 28691 Madrid, Spain 
direct application of formulas and require the participation of evaluators to qualify the specifications provided in the proposals. In those cases it is necessary for the implementation of a method to code the evaluators' opinions and integrate those opinions in a unique value. In the public sector, it is necessary to fulfill several legal requisite ${ }^{[1]}$ depending on the legislation of the country. In particular, in the European Union it is necessary to ensure that the bidding process conforms to the principles of transparency, non-discrimination and equal treatment, ${ }^{[2]}$ making necessary to specify the scoring rules and weights in advance. ${ }^{[3,4]}$

Nevertheless, even with a good knowledge of the required technology, it is difficult to foresee the variability of some specifications among offers (for example, some important characteristics may be equally specified by all of the potential suppliers). This may conduct to an unbalanced assignation of weights to the evaluation criteria, conferring high weights to non-significant criteria with the consequent loss of resolution in the evaluation and, in some cases, the selection of an option that is not necessarily the best. The direct solution to this problem consists in the modification of weights during the evaluation process but this is not acceptable if, according to the legislation, the scoring rules and weights must be set in advance.

The objectives of the research were the implementation of a method for the evaluation of offers, including the adaption of weights as part of the evaluation process without violating the principles of transparency and non-discrimination that are generally required by the legislation; the integration of quantitative and qualitative criteria in a flexible procedure that admits crisp values, different types of intervals and linguistic values from different evaluators; and the verification for possible rank reversals by a simple procedure. We propose the use of trapezoidal fuzzy numbers (TFN) for the simultaneous implementation of different types of evaluations, and variable weights analysis (VWA) for the subsequent adjustment of weights.

$\mathrm{VWA}^{[5]}$ is a method that implements weights adaption procedures according to a state variable weight vector. ${ }^{[6-8]}$

Fuzzy logic ${ }^{[9]}$ substitutes the classic two-valued logic (true and false) with continuous graded membership functions that go from absolute true to absolute false. Fuzzy logic is useful for representing imprecise knowledge and linguistic terms. ${ }^{[10]} \mathrm{TFN}^{[11,12]}$ can be used to capture and represent information from different sources supplied in varied forms that can be aggregated. Centroid function permits the defuzzification of fuzzy numbers. ${ }^{[13]}$

Rank reversal ${ }^{[14]}$ is a common problem in decision making that consists in an inversion in the position in a ranking when options are suppressed or new ones are added.

The contribution of the research described in this paper consist in the development of a method for the automatic adap-

Published by Sciedu Press tion of weights based on the VWA method to emphasize significant criteria; and the implementation of trapezoidal fuzzy numbers and centroid function for the codification, aggregation and defuzzification of evaluations simultaneously performed by different evaluators in a varied manner. A hierarchy of criteria is implemented to facilitate the assignation of weights. The procedure and formulas can be previously set in the RFP preserving the principles of transparency and non-discrimination that are required in the public sector.

The rest of the paper is organized as follows: In Section 2, a literature review is presented. Section 3 describes the proposed method. Section 4 presents a numerical example including a rank reversal analysis. Finally, Section 5 contains the conclusions and possible directions for future research.

\section{Literature review}

Several methods base on fuzzy logic are applied to the evaluation and selection of suppliers. ${ }^{[15-17]}$

Chen et al. ${ }^{[6]}$ presented a model for the evaluation of offers based on "Variable Weights-TOPSIS". In the first step, the criteria values supplied in an offer are normalized using linear formulas. A state variable weights vector is implemented by a punitive exponent-type formula to modify the weights of the criteria that evaluate an option. Every option has its own state variable weights vector that modifies its criteria. Every criterion is modified depending on the difference between the normalized value of the criterion in that option and the arithmetic mean among all the normalized values of criteria for the same option. This procedure is sensible to the decrease of a single factor at low level but stagnates on the increase of single factors at high level, emphasizing offers with more balanced criteria. Finally, TOPSIS is applied to rank the options. The obtained ranking may vary with the level of punishment introduced in the exponent-type formula.

Chen et al. ${ }^{[18]}$ used linguistic values associated to trapezoidal and triangular fuzzy numbers in a method based on fuzzy TOPSIS. Guneri et al. ${ }^{[19]}$ expressed linguistic values in TFN to assess weights and ratings of suppliers in a linear programing method. Wang et al. ${ }^{[20]}$ used TFN in a TOPSIS based method for supply selection; Sanayei et al. ${ }^{[21]}$ used TFN associated to linguistic terms in the implementation of a group decision making based on VIKOR. Liao and $\mathrm{Kao}^{[22]}$ use trapezoidal and fuzzy triangular numbers associated to linguistic values in a method based on the combination of TOPSIS and multi-choice goal programing (MCGP).

Luukka $^{[23]}$ developed a method using TFN in relation to linguistic values; the method is a new approach to TOPSIS in which the distance between a real option and the ideal positive and negative options is obtained by similarity of trapezoidal fuzzy numbers. 
Using trapezoidal and fuzzy triangular numbers associated to linguistic values, Amindoust et al. ${ }^{[24]}$ implemented an array of fuzzy inference systems (FIS) to rank suppliers. Ferreira and Borenstein ${ }^{[25]}$ implemented a method based on the integration of influence diagram and fuzzy logic to rank and evaluate suppliers; linguistic terms for the importance weight of criteria are associated to TFN. Pattnaik ${ }^{[26]}$ converted linguistic values into TFN, using fuzzy mean for aggregation to evaluate and rank suppliers.

\section{Proposed method}

The proposed method is based on the following algorithm: Original weights are assigned to every final criterion (steps 1 and 2). Quantitative criteria are evaluated using linear functions (Step 4). Evaluations for qualitative criteria are transformed in TFN; normalized crisp values are obtained by centroid calculation and linear functions (Step 5). The original weight of every criterion is modified according to the dispersion of the evaluations among options; every option is assigned a value from the weighted average ${ }^{[26]}$ of the values obtained for the option in relation to the final evaluation criteria (Step 6). The results may be checked for rank reversal by the suppression of options and the verification of the resulting rank.

The proposed method is implemented as follows:

Step 1: The evaluation criteria are organized in a hierarchy. ${ }^{[27]}$ To facilitate the assignation of weights, groups in the hierarchy are organized to have not more than four elements.

Step 2: Weights are assigned to every criterion. Due to the small number of criteria in every group, weights can be directly assigned. The sum of the weights within every group equals 1 . Every criterion $C_{n}$ in the lower level of every line of the hierarchy (final criterion) is assigned a global weight as a result of the aggregation of all the relative weights in its line: ${ }^{[28]}$

$$
W_{n}=\prod_{i=1}^{L} w_{i}
$$

where $W_{n}$ is the global weight of the final criterion $C_{n}, w_{i}$ are the partial weights of the criteria in its line in the hierarchy, and $L$ is the number of levels in its line in the hierarchy. The RFP will include the global weights of the final criteria, as well as the evaluation formulas and the procedure for weight compensation that are detailed in steps 4 to 6 .

Step 3: After receiving the offers, all the options that fail on fulfilling any of the compulsory specifications are discarded.

Step 4: For the evaluation of quantitative criteria, we propose the use of the following linear formulas that normalize the values ${ }^{[6]}$ and provide the highest resolution. ${ }^{[29]}$ For numerical characteristics with a negative perspective (the lower the best), we apply a normalized linear formula: ${ }^{[30]}$

$$
V_{m n}=\frac{\max \left(x_{n}\right)-x_{m n}}{\max \left(x_{n}\right)-\min \left(x_{n}\right)}
$$

where $V_{m n}$ is the numerical value assigned to option $O_{m}$ in relation to criteria $C_{n} ; x_{m n}$ is the numerical specification of criteria $C_{n}$ for option $O_{m} ; \min \left(x_{n}\right)$ is the minimum value of specification $x_{n}$ among all the options; and $\max \left(x_{n}\right)$ is the maximum value of specification $x_{n}$ among all the options. For numerical characteristics with a positive perspective (the higher the best) we apply the following normalized linear formula: ${ }^{[30]}$

$$
V_{m n}=\frac{x_{m n}-\min \left(x_{n}\right)}{\max \left(x_{n}\right)-\min \left(x_{n}\right)}
$$

Every final criterion is evaluated with values belonging to the interval $[0,1]$. Both formulas assign $V_{m n}=1$ to the best option and $V_{m n}=0$ to the worst. When all the values are the same, $x_{m n}=\max \left(x_{m n}\right)=\min \left(x_{m n}\right)$ and $V_{m n}=0$.

Criteria consisting in ranges of values can be split in two different criteria (top and bottom values) with their own weights, or can be assigned a unique value either from the mean of the evaluation of top and bottom values or from a weighted mean of their evaluations.

Step 5: Qualitative criteria are evaluated by evaluators who may use any of the following four types of values: crisp numerical values, simple intervals, intervals with a preferred subinterval, intervals with a preferred single value, and linguistic values. Every evaluator can freely select the type of value and all five types can be simultaneously used by different evaluators.

All the values are associated to trapezoidal fuzzy numbers $\tilde{T}=(a, b, c, d)^{[11]}$ with the following membership function: ${ }^{[12]}$

$$
\mu_{\tilde{T}}(x)=\left\{\begin{array}{cc}
0 & x \leq a \\
\frac{x-a}{b-a} & a<x<b \\
1 & b \leq x \leq c \\
\frac{x-d}{c-d} & c<x<d \\
0 & x \geq d
\end{array}\right.
$$

Every evaluator $e_{j}$ emits a judgment on every option $O_{m}$ in relation to criterion $C_{n}$. Every judgment is transformed in a trapezoidal value: ${ }^{[31]}$

$$
\tilde{v_{m}}(n) e_{j}=\left(a_{m n e_{j}}, b_{m n e_{j}}, c_{m n e_{j}}, d_{m n e_{j}}\right)
$$

For crisp values: $a=b=c=d$; for simple intervals: $a=b<c=d$; for intervals with a preferred subinterval (trapezoidal fuzzy number): $a<b<c<d$; for intervals with a preferred single value (fuzzy triangular number): $a<b=c<d$. 
For linguistic values there are pre-assigned fuzzy triangular numbers $a<b=c<d$ according to Table 1 .

To obtain a unique normalized value $V_{m n}$ for every option in relation to every final criterion, a unique trapezoidal fuzzy number $\tilde{T}_{m n}$ is obtained. Considering that the same weight is assigned to all of the evaluators, the aggregation is performed by the arithmetic mean of all the trapezoidal fuzzy numbers assigned by the evaluators $e_{j}$ to that specific option $O_{m}$ in relation to that specific criterion $C_{n}:^{[32,33]}$

$$
\tilde{T_{m n}}=\left(A_{m n}, B_{m n}, C_{m n}, D_{m n}\right)=\left(\frac{1}{E} \sum_{j=1}^{E} a_{m n e_{j}}, \frac{1}{E} \sum_{j=1}^{E} b_{m n e_{j}}, \frac{1}{E} \sum_{j=1}^{E} c_{m n e_{j}}, \frac{1}{E} \sum_{j=1}^{E} d_{m n e_{j}}\right)
$$

where $E$ is the total number of evaluators that have per- $\mu_{\tilde{T}}(x):^{[13]}$

formed the evaluation of option $O_{m}$ in relation to criterion $C_{n}$.

Finally, a crisp value is obtained by calculation of the centroid of the corresponding trapezoidal membership function

$$
x_{m n}=\frac{\int_{-\infty}^{\infty} x \mu_{T_{m n}^{\sim}}(x) d x}{\int_{-\infty}^{\infty} \mu_{T_{m n}^{\tilde{m}}}(x) d x}
$$

$$
x_{m n}=\frac{1}{3}\left[A_{m n}+B_{m n}+C_{m n}+D_{m n}-\frac{D_{m n} C_{m n}-A_{m n} B_{m n}}{\left(D_{m n}+C_{m n}\right)-\left(A_{m n}+B_{m n}\right)}\right]
$$

Table 1: Linguistic values

\begin{tabular}{llllll}
\hline Linguistic & $\begin{array}{l}\text { Very } \\
\text { Low }\end{array}$ & Low & Medium & High & $\begin{array}{l}\text { Very } \\
\text { High }\end{array}$ \\
\hline Mnemonic & $\mathrm{vL}$ & $\mathrm{L}$ & $\mathrm{M}$ & $\mathrm{H}$ & $\mathrm{vH}$ \\
& $(0,0,0$, & $(0,0.25$, & $(0.25,0.5$, & $(0.5,0.75$, & $(0.75,1$, \\
TFN & $0.25)$ & $0.25,0.5)$ & $0.5,0.75)$ & $0.75,1)$ & $1,1)$ \\
\hline
\end{tabular}

Finally, a normalized value $V_{m n}$ is obtained applying Eq. (3) for characteristics with a positive perspective or Eq. (2) for characteristics with a negative perspective.

As for quantitative criteria every final criterion receives a value belonging to the interval $[0,1]$.

Step 6: Every option $O_{m}$ is assigned a normalized compensated weighted value $W_{n}^{\prime} V_{m n}$ in relation to every final criterion $C_{n}$. The final result of the evaluation $U_{m}$ of option $O_{m}$ will be: ${ }^{[3,34]}$

$$
U_{m}=\sum_{n=1}^{N} W_{n}^{\prime} V_{m n} ; \sum_{n=1}^{N} W_{n}^{\prime}=1
$$

where $N$ is the total number of final criteria $C_{n} ; V_{m n}$ is the unique normalized value assigned to option $O_{m}$ in relation to final criterion $C_{n}$, that was obtained in Step 4 for quantitative criteria and in Step 5 for qualitative criteria; and $W_{n}^{\prime}$ is the normalized compensated weight assigned to criterion $C_{n}$ according to the following equation: ${ }^{[35,36]}$

$$
W_{n}^{\prime}=\frac{S\left(x_{n}\right) W_{n}}{\sum_{i=1}^{N} S\left(x_{i}\right) W_{i}}
$$

$S(x)$ defines the state variable weight vector. ${ }^{[8]}$ We implement an exponent type incentive state variable weight vec-

Published by Sciedu Press tor: $^{[6]}$

$$
S\left(x_{n}\right)=e^{\alpha \frac{\sigma_{n}}{\left|x_{n}\right|}} ; \alpha \geq 0
$$

$\alpha$ is the varying level of weights and $\sigma$ is the dispersion calculated by the well-known standard deviation formula:

$$
\sigma_{n}=\left[\sum_{m=1}^{M} \frac{\left(x_{m n}-\overline{x_{n}}\right)^{2}}{M}\right]^{0.5}
$$

$M$ is the total number of valid options and $\left|\overline{x_{n}}\right|$ is the absolute value of the mean:

$$
\left|\overline{x_{n}}\right|=\left|\sum_{m=1}^{M} \frac{x_{m n}}{M}\right|
$$

When $\alpha=0$, weights are not compensated $\left(W_{n}^{\prime}=W_{n}\right)$ and the procedure implements the classic approach.

When a criterion contains more than one value, we use the quadratic addition of the values:

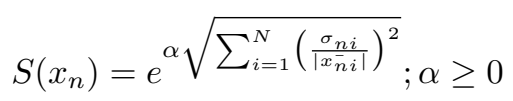

\section{Case study}

We show the implementation of the proposed methodology through a numerical example using data from a public tender for the supply of customized barcode readers for their integration with a lottery terminal. 


\section{Step 1:}

We organized the evaluation criteria in a hierarchy:



Step 2:

Table 2: Partial weights $w_{i}$ and global weights $W_{n}$

\begin{tabular}{llll}
\hline$w_{i}$ & & & $w_{n}$ \\
\hline & $w_{1.1}=0.2$ & & $w_{1.1}=0.040$ \\
& $w_{1.2}=0.2$ & $w_{1.2 .1}=0.6$ & $w_{1.2 .1}=0.024$ \\
& & $w_{1.2 .2}=0.15$ & $w_{1.2 .2}=0.006$ \\
$w_{1}=0.2$ & & $w_{1.2 .3}=0.25$ & $w_{1.2 .3}=0.010$ \\
& & $w_{1.3 .1}=0.2$ & $w_{1.3 .1}=0.014$ \\
& $w_{1.3}=0.35$ & $w_{1.3 .2}=0.3$ & $w_{1.3 .2}=0.021$ \\
& & $w_{1.3 .3}=0.2$ & $w_{1.3 .3}=0.014$ \\
& & $w_{1.3 .4}=0.3$ & $w_{1.3 .4}=0.021$ \\
& $w_{1.4}=0.25$ & & $w_{1.4}=0.050$ \\
$w_{2}=0.3$ & $w_{2.1}=0.15$ & & $w_{2.1}=0.045$ \\
& $w_{2.3}=0.6$ & & $w_{2.2}=0.180$ \\
& $w_{2.4}=0.15$ & & $w_{2.3}=0.030$ \\
$w_{3}=0.3$ & & & $w_{2.4}=0.045$ \\
$w_{4}=0.2$ & & & $w_{3}=0.300$ \\
\hline
\end{tabular}

Table 2 shows the assigned partial weights $w_{i}$, and the global weights $W_{n}$ that were calculated for every final criteria $C_{n}$.

\section{Step 3:}

The options that did not comply with the requested specifications were discarded. Four options $\left(\mathrm{O}_{1}, \mathrm{O}_{2}, \mathrm{O}_{3}, \mathrm{O}_{4}\right)$ continued the evaluation process.

\section{Step 4:}

The numerical data supplied in the offers are shown in Table 3.

Table 3: Numerical specifications $x_{m n}$

\begin{tabular}{lllll}
\hline$C_{n}$ & $\mathrm{O}_{1}$ & $\mathrm{O}_{2}$ & $\mathrm{O}_{3}$ & $\mathrm{O}_{4}$ \\
\cline { 2 - 5 } & $x_{1 n}$ & $x_{2 n}$ & $x_{3 n}$ & $x_{4 n}$ \\
\hline$C_{1.1}$ & - & - & - & - \\
$C_{1.2 .1}$ & $0 / 50$ & $0 / 50$ & $0 / 50$ & $0 / 40$ \\
$C_{1.2 .2}$ & $-40 / 70$ & $-20 / 70$ & $-40 / 70$ & $-40 / 60$ \\
$C_{1.2 .3}$ & $0 / 95$ & $0 / 90$ & $0 / 95$ & $0 / 95$ \\
$C_{1.3 .1}$ & 16 & 16 & 15 & 13 \\
$C_{1.3 .2}$ & 1.5 & 1.8 & 1.8 & 1.5 \\
$C_{1.3 .3}$ & $\mathrm{IP} 42$ & $\mathrm{IP} 52$ & $\mathrm{IP} 41$ & $\mathrm{IP} 42$ \\
$C_{1.3 .4}$ & 86.000 & 100.000 & 100.000 & 96.890 \\
$C_{1.4}$ & - & - & - & - \\
$C_{2.1}$ & 25 & 25 & 20 & 35 \\
$C_{2.2}$ & 63.5 & 63.5 & 610 & 10 \\
$C_{2.3}$ & 4 & 4 & 5 & 5 \\
$C_{2.4}$ & $65 / 180 / 60$ & $40 / 180 / 40$ & $45 / 180 / 65$ & $60 / 180 / 70$ \\
$C_{3}$ & 110 & 127.08 & 173.16 & 130 \\
$C_{4}$ & - & - & - & - \\
\hline
\end{tabular}

The evaluation of numerical specifications was performed by the application of Eqs. (2) and (3).

$C_{1.2 .2}$ was evaluated by the mean of the evaluation of its extremes. $C_{1.2 .1}$ and $C_{1.2 .3}$ were evaluated by their top value (the bottom value was the same for the three options). $C_{2.4}$ was evaluated by the mean of the evaluation of two of its values (one of the three values was the same for the four options). $C_{1.3 .3}$ contains two numbers that are not numerical values but codes of the level of protection: one against the intrusion of solids and the other against the intrusion of water. Nevertheless, we considered them as numerical values and obtained the evaluation from the mean of the two values.

\section{Step 5:}

Tables 4 to 6 show the evaluation of options $O_{m}$ in relation to $C_{1.1}, C_{1.4}$ and $C_{4}$. Evaluations were performed by six different evaluators $e_{j}$ using crisp numbers, simple intervals, intervals with preference subintervals and linguistic 
terms.

Table 4: Judgments emitted by 6 evaluators $e_{j}$ for options $O_{m}$ in relation to final criterion $C_{1.1}$

\begin{tabular}{lllll}
\hline & $\mathrm{O}_{1}$ & $\mathrm{O}_{2}$ & $\mathrm{O}_{3}$ & $O_{4}$ \\
\hline$e_{1}$ & 0.6 & 0.8 & 0.9 & 0.5 \\
$e_{2}$ & $\mathrm{M}$ & $\mathrm{H}$ & $\mathrm{vH}$ & $\mathrm{M}$ \\
$e_{3}$ & $(0.5,0.75)$ & $(0.7,0.9)$ & $(0.8,1)$ & $(0.75,0.8)$ \\
$e_{4}$ & $\mathrm{M}$ & $\mathrm{M}$ & $\mathrm{vH}$ & $\mathrm{M}$ \\
$e_{5}$ & $\mathrm{M}$ & $\mathrm{H}$ & $\mathrm{vH}$ & $\mathrm{M}$ \\
$e_{6}$ & $(0.6,0.7,0.75$, & $(0.75,0.8$, & $(0.75,0.9$, & $(0.5,0.65$, \\
\hline
\end{tabular}

Table 5: Judgments emitted by 6 evaluators $e_{j}$ for options $O_{m}$ in relation to final criterion $C_{1.4}$

\begin{tabular}{lllll}
\hline & $\mathrm{O}_{1}$ & $\mathrm{O}_{2}$ & $\mathrm{O}_{3}$ & $\mathrm{O}_{4}$ \\
\hline$e_{1}$ & 0.4 & 0.4 & 0.75 & 0.75 \\
$e_{2}$ & $\mathrm{M}$ & $\mathrm{M}$ & $\mathrm{H}$ & $\mathrm{H}$ \\
$e_{3}$ & $(0.3,0.5)$ & $(0.3,0.5)$ & $(0.6,0.8)$ & $(0.6,0.8)$ \\
$e_{4}$ & $\mathrm{~L}$ & $\mathrm{~L}$ & $\mathrm{M}$ & $\mathrm{M}$ \\
$e_{5}$ & $\mathrm{M}$ & $\mathrm{M}$ & $\mathrm{M}$ & $\mathrm{M}$ \\
& $(0.5,0.6$, & $(0.5,0.6$, & $(0.8,0.85$, & $(0.8,0.85$, \\
$e_{6}$ & $0.65,0.7)$ & $0.65,0.7)$ & $0.87,0.9)$ & $0.87,0.9)$ \\
\hline
\end{tabular}

Table 6: Judgments emitted by 3 evaluators $e_{j}$ for options $O_{m}$ in relation to final criterion $C_{4}$

\begin{tabular}{lllll}
\hline & $\mathrm{O}_{1}$ & $\mathrm{O}_{2}$ & $\mathrm{O}_{3}$ & $\mathrm{O}_{4}$ \\
\hline$e_{1}$ & 0.2 & 0.9 & 0.9 & 0.2 \\
$e_{2}$ & $\mathrm{~L}$ & $\mathrm{vH}$ & $\mathrm{vH}$ & $\mathrm{L}$ \\
$e_{3}$ & $(0,0.25)$ & $(0.9,1)$ & $(0.9,1)$ & $(0,0.25)$ \\
\hline
\end{tabular}

Tables 7 to 9 show the procedures to obtain unique normalized numerical values $V_{m n}$ for options $O_{m}$ in relation to $C_{1.1}, C_{1.4}$ and $C_{4}$.

\section{Step 6:}

We previously set the value of the varying level of weights to $\alpha=2$. Table 10 shows the calculation of the overall evaluation of every option.

For the calculation of the state variable weights vector we used Eq. (11). For $C_{1.2 .2}, C_{1.3 .3}$ and $C_{2.4}$ we use Eq. (14).

\section{Analysis of results}

Table 11 shows the overall evaluation $U_{m}$ for different values of the weight modification level $\alpha$. It can be observed that the resulting ranking is different for the classic approach with original non-compensated weights $(\alpha=0)$. For compensated weights, as the value of weight modification level $\alpha$ increases, the overall evaluation $U_{3}$ of the first positioned option $\mathrm{O}_{3}$ is separated from the rest.

Table 7: Procedure to obtain a unique normalized numerical value $V_{m 1.1}$ for every option $O_{m}$

\begin{tabular}{lllll}
\hline & $O_{1}$ & $O_{2}$ & $O_{3}$ & $O_{4}$ \\
\cline { 2 - 5 } & $\tilde{v}_{1(1.1) e_{j}}$ & $\tilde{v}_{2(1.1) e_{j}}$ & $\tilde{v}_{3(1.1) e_{j}}$ & $\tilde{v}_{4}(1.1) e_{j}$ \\
\hline \multirow{2}{*}{$e_{1}$} & $(0.6,0.6$, & $(0.8,0.8$, & $(0.9,0.9$, & $(0.5,0.5,0.5$, \\
& $0.6,0.6)$ & $0.8,0.8)$ & $0.9,0.9)$ & $0.5)$ \\
$e_{2}$ & $(0.25,0.5$, & $(0.5,0.75$, & $(0.75,1,1$, & $(0.25,0.5$, \\
& $0.5,0.75)$ & $0.75,1)$ & $1)$ & $0.5,0.75)$ \\
$e_{3}$ & $(0.5,0.5$, & $(0.7,0.7$, & $(0.8,0.8,1$, & $(0.75,0.75$, \\
& $0.75,0.75)$ & $0.9,0.9)$ & $1)$ & $0.8,0.8)$ \\
$e_{4}$ & $(0.25,0.5$, & $(0.25,0.5$, & $(0.75,1,1$, & $(0.25,0.5$, \\
& $0.5,0.75)$ & $0.5,0.75)$ & $1)$ & $0.5,0.75)$ \\
$e_{5}$ & $(0.25,0.5$, & $(0.5,0.75$, & $(0.75,1,1$, & $(0.25,0.5$, \\
& $0.5,0.75)$ & $0.75,1)$ & $1)$ & $0.5,0.75)$ \\
$e_{6}$ & $(0.6,0.7$, & $(0.75,0.8$, & $(0.75,0.9$, & $(0.5,0.65$, \\
$\tilde{T}_{m 1.1}$ & $0.75,0,8)$ & $0.9,1)$ & $0.95,1)$ & $0.6,0.75)$ \\
\multirow{2}{*}{$X_{m 1.1}$} & $(0.41,0.55$, & $(0.58,0.72$, & $(0.78,0.93$, & $(0.42,0.57$, \\
$V_{m 1.1}$ & $0.6,0.73)$ & $0.77,0.91)$ & $0.98,0.98)$ & $0.57,0.72)$ \\
\hline
\end{tabular}

Table 8: Procedure to obtain a unique normalized numerical value $V_{m 1.4}$ for every option $O_{m}$

\begin{tabular}{lllll}
\hline & $O_{1}$ & $O_{2}$ & $O_{3}$ & $O_{4}$ \\
\cline { 2 - 5 } & $\tilde{v}_{1}(1.4) e_{j}$ & $\tilde{v}_{2}(1.4) e_{j}$ & $\tilde{v}_{3}(1.4) e_{j}$ & $\tilde{v}_{4}(1.4) e_{j}$ \\
\hline \multirow{2}{*}{$e_{1}$} & $(0.4,0.4$, & $(0.4,0.4$, & $(0.75,0.75$, & $(0.75,0.75$, \\
& $0.4,0.4)$ & $0.4,0.4)$ & $0.75,0.75)$ & $0.75,0.75)$ \\
$e_{2}$ & $(0.25,0.5$, & $(0.25,0.5$, & $(0.5,0.75$, & $(0.5,0.75$, \\
& $0.5,0.75)$ & $0.5,0.75)$ & $0.75,1)$ & $0.75,1)$ \\
$e_{3}$ & $(0.3,0.3$, & $(0.3,0.3$, & $(0.6,0.6$, & $(0.6,0.6,0.8$, \\
& $0.5,0.5)$ & $0.5,0.5)$ & $0.8,0.8)$ & $0.8)$ \\
$e_{4}$ & $(0,0.25$, & $(0,0.25$, & $(0.25,0.5$, & $(0.25,0.5$, \\
& $0.25,0.5)$ & $0.25,0.5)$ & $0.5,0.75)$ & $0.5,0.75)$ \\
$e_{5}$ & $(0.25,0.5$, & $(0.25,0.5$, & $(0.25,0.5$, & $(0.25,0.5$, \\
& $0.5,0.75)$ & $0.5,0.75)$ & $0.5,0.75)$ & $0.5,0.75)$ \\
$e_{6}$ & $(0.5,0.6$, & $(0.5,0.6$, & $(0.8,0.85$, & $(0.8,0,85$, \\
& $0.65,0.7)$ & $0.65,0.7)$ & $0.87,0.9)$ & $0,87,0.9)$ \\
$\tilde{T}_{m 1.4}$ & $(0.28,0.43$, & $(0.28,0.43$, & $(0.53,0.66$, & $(0.53,0.66$, \\
\multirow{2}{*}{$x_{m 1.4}$} & $0.47,0.6)$ & $0.47,0.64)$ & $0.7,0.83)$ & $0.7,0.83)$ \\
$V_{m 1.4}$ & 0.443 & 0.443 & 0.676 & 0.676 \\
\hline
\end{tabular}

Table 12 shows the verification for rank reversal for two values of the weight modification level ( $\alpha=0$ and $\alpha=1$ ). Options are consecutively suppressed to observe the effects in the remaining options in order to detect possible changes in the ranking. A case of rank reversal is detected with the original non-compensated weights $(\alpha=0)$ when $O_{3}$ is suppressed. In a similar way, in Table 13, pairs of options are suppressed to detect changes in the ranking of the remaining options. A case of rank reversal is detected with the origi- 
nal non-compensated weights $(\alpha=0)$ when $O_{3}$ and $O_{4}$ are suppressed.

Table 9: Procedure to obtain a unique normalized numerical value $V_{m 4}$ for every option $O_{m}$

\begin{tabular}{|c|c|c|c|c|}
\hline & $\tilde{v}_{1}(4) e_{j}$ & $\tilde{v}_{2}(4) e_{j}$ & $\tilde{v}_{3}(4) e_{j}$ & $\tilde{v}_{4}(4) e_{j}$ \\
\hline$e_{1}$ & $\begin{array}{l}(0.2,0.2 \\
0.2,0.2)\end{array}$ & $\begin{array}{l}(0.9,0.9 \\
0.9,0.9)\end{array}$ & $\begin{array}{l}(0.9,0.9 \\
0.9,0.9)\end{array}$ & $\begin{array}{l}(0.2,0.2 \\
0.2,0.2)\end{array}$ \\
\hline$e_{2}$ & $\begin{array}{l}(0,0.25 \\
0.25,0.5)\end{array}$ & $\begin{array}{l}(0.75,1, \\
1,1)\end{array}$ & $\begin{array}{l}(0.75,1 \\
1,1)\end{array}$ & $\begin{array}{l}(0,0.25, \\
0.25,0.5)\end{array}$ \\
\hline$e_{3}$ & $\begin{array}{l}(0,0,0.25 \\
0.25)\end{array}$ & $\begin{array}{l}(0.9,0.9 \\
1,1)\end{array}$ & $\begin{array}{l}(0.9,0.9 \\
1,1)\end{array}$ & $\begin{array}{l}(0,0,0.25, \\
0.25)\end{array}$ \\
\hline$\tilde{T}_{m 4}$ & $\begin{array}{l}(0.07,0.15 \\
0.23,0.32)\end{array}$ & $\begin{array}{l}(0.85 \\
0.93 \\
0.97 \\
0.97)\end{array}$ & $\begin{array}{l}(0.85 \\
0.93, \\
0.97 \\
0.97)\end{array}$ & $\begin{array}{l}(0.07,0.15 \\
0.23,0.32)\end{array}$ \\
\hline$x_{m 4}$ & 0.192 & 0.925 & 0.925 & 0.192 \\
\hline$V_{m 4}$ & 0 & 1 & 1 & 0 \\
\hline
\end{tabular}

Table 10: Calculation of the overall evaluation $U_{m}$ of every option $O_{m}$ for $\alpha=2$

\begin{tabular}{|c|c|c|c|c|c|c|c|c|c|}
\hline & & & & & & $O_{1}$ & $\mathrm{O}_{2}$ & $\mathrm{O}_{3}$ & $\mathrm{O}_{4}$ \\
\hline$C_{n}$ & $\frac{\sigma_{n}}{\left|\overline{x_{n}}\right|}$ & $S\left(x_{n}\right)$ & $W_{n}$ & $S\left(x_{n}\right) W_{n}$ & $W_{n}^{\prime}$ & $V_{1 n}$ & $V_{2 n}$ & $V_{3 n}$ & $V_{4 n}$ \\
\hline$C_{1.1}$ & 0.203 & 1.501 & 0.040 & 0.0600 & 0.0146 & 0.017 & 0.516 & 1.000 & 0.000 \\
\hline$C_{1.2 .1}$ & 0.000 & 1.200 & 0.024 & 0.0288 & 0.0070 & 1.000 & 1.000 & 1.000 & 0.000 \\
\hline$C_{1.2 .2}$ & 0.247 & 1.667 & 0.006 & 0.0100 & 0.0024 & 1.000 & 0.500 & 1.000 & 0.500 \\
\hline$C_{1.2 .3}$ & 0.000 & 1.047 & 0.010 & 0.0105 & 0.0025 & 1.000 & 0.000 & 1.000 & 1.000 \\
\hline$C_{1.3 .1}$ & 0.082 & 1.177 & 0.014 & 0.0165 & 0.0040 & 1.000 & 1.000 & 0.667 & 0.000 \\
\hline$C_{1.3 .2}$ & 0.091 & 1.199 & 0.021 & 0.0252 & 0.0061 & 0.000 & 1.000 & 1.000 & 0.000 \\
\hline$C_{1.3 .3}$ & 0.102 & 1.708 & 0.014 & 0.0239 & 0.0058 & 0.500 & 1.000 & 0.000 & 0.500 \\
\hline$C_{1.3 .4}$ & 0.060 & 1.128 & 0.021 & 0.0237 & 0.0058 & 0.000 & 1.000 & 1.000 & 0.778 \\
\hline$C_{1.4}$ & 0.208 & 1.515 & 0.050 & 0.0758 & 0.0184 & 0.000 & 0.000 & 1.000 & 1.000 \\
\hline$C_{2.1}$ & 0.208 & 1.515 & 0.045 & 0.0682 & 0.0166 & 0.333 & 0.333 & 0.000 & 1.000 \\
\hline$C_{2.2}$ & 1.314 & 13.838 & 0.180 & 2.4909 & 0.6051 & 0.089 & 0.089 & 1.000 & 0.000 \\
\hline$C_{2.3}$ & 0.111 & 1.249 & 0.030 & 0.0375 & 0.0091 & 1.000 & 1.000 & 0.000 & 0.000 \\
\hline$C_{2.4}$ & 0.196 & 1.736 & 0.045 & 0.0781 & 0.0190 & 0.833 & 0.000 & 0.517 & 0.900 \\
\hline$C_{3}$ & 0.172 & 1.412 & 0.300 & 0.4235 & 0.1029 & 1.000 & 0.730 & 0.000 & 0.683 \\
\hline $\mathrm{C}_{4}$ & 0.657 & 3.720 & 0.200 & 0.7439 & 0.1807 & 0.000 & 1.000 & 1.000 & 0.000 \\
\hline$U_{m}$ & & & & & & 0.206 & 0.362 & 0.855 & 0.133 \\
\hline
\end{tabular}

Table 11: Overall evaluation $U_{m}$ for different values of the weight modification level $\alpha$

\begin{tabular}{llllllll}
\hline \multicolumn{7}{c}{$\alpha$} \\
\hline & 0.0 & 0.5 & 1.0 & 1.5 & 2.0 & 2.5 & 3.0 \\
\hline$O_{1}$ & 0.46 & 0.40 & 0.33 & 0.26 & 0.21 & 0.16 & 0.13 \\
$O_{2}$ & 0.60 & 0.55 & 0.50 & 0.43 & 0.36 & 0.30 & 0.24 \\
$O_{3}$ & 0.58 & 0.65 & 0.72 & 0.79 & 0.86 & 0.90 & 0.94 \\
$O_{4}$ & 0.38 & 0.32 & 0.25 & 0.19 & 0.13 & 0.09 & 0.06 \\
\hline
\end{tabular}

Table 12: Rank reversal verification by suppression of one option

\begin{tabular}{cccccccc}
\hline & & Original & \multicolumn{3}{c}{$U_{m}$ suppressing one option } & Original \\
\cline { 5 - 7 } & & $U_{m}$ & $O_{1}$ & $O_{2}$ & $O_{3}$ & $O_{4}$ & Position \\
\hline \multirow{2}{*}{$\alpha=0$} & $U_{1}$ & 0.46 & $\mathrm{X}$ & 0.44 & $\mathbf{0 . 6}$ & 0.45 & 3 \\
& $U_{2}$ & 0.60 & 0.68 & $\mathrm{X}$ & $\mathbf{0 . 5 7}$ & 0.58 & 1 \\
& $U_{3}$ & 0.58 & 0.59 & 0.58 & $\mathrm{X}$ & 0.56 & 2 \\
& $U_{4}$ & 0.38 & 0.44 & 0.39 & 0.16 & $\mathrm{X}$ & 4 \\
& $U_{1}$ & 0.33 & $\mathrm{X}$ & 0.32 & 0.54 & 0.34 & 3 \\
& $U_{2}$ & 0.50 & 0.56 & $\mathrm{X}$ & 0.66 & 0.50 & 2 \\
& $U_{3}$ & 0.72 & 0.70 & 0.72 & $\mathrm{X}$ & 0.67 & 1 \\
& $U_{4}$ & 0.25 & 0.32 & 0.26 & 0.14 & $\mathrm{X}$ & 4 \\
\hline
\end{tabular}

Table 13: Rank reversal verification by suppression of two options

\begin{tabular}{|c|c|c|c|c|c|c|c|c|c|}
\hline & & \multirow{2}{*}{$\begin{array}{l}\text { Original } \\
U_{m}\end{array}$} & \multicolumn{6}{|c|}{$U_{m}$ suppressing two options } & \multirow{2}{*}{$\begin{array}{l}\text { Original } \\
\text { Position }\end{array}$} \\
\hline & & & $O_{1} O_{2}$ & $O_{1} O_{3}$ & $O_{1} O_{4}$ & $\mathrm{O}_{2} \mathrm{O}_{3}$ & $\mathrm{O}_{2} \mathrm{O}_{4}$ & $\mathrm{O}_{3} \mathrm{O}_{4}$ & \\
\hline \multirow{4}{*}{$\alpha=0$} & $U_{1}$ & 0.46 & $\mathrm{X}$ & $\mathrm{x}$ & $\mathrm{x}$ & 0.58 & 0.43 & 0.36 & 3 \\
\hline & $U_{2}$ & 0.60 & $\mathrm{x}$ & 0.83 & 0.62 & $\mathrm{x}$ & $\mathrm{x}$ & 0.28 & 1 \\
\hline & $U_{3}$ & 0.58 & 0.56 & $\mathrm{x}$ & 0.53 & $\mathrm{x}$ & 0.56 & $\mathrm{X}$ & 2 \\
\hline & $U_{4}$ & 0.38 & 0.45 & 0.15 & $\mathrm{x}$ & 0.16 & $\mathrm{x}$ & $\mathrm{x}$ & 4 \\
\hline \multirow{4}{*}{$\alpha=1$} & $U_{1}$ & 0.33 & $\mathrm{x}$ & $\mathrm{x}$ & $\mathrm{x}$ & 0.64 & 0.34 & 0.33 & 3 \\
\hline & $U_{2}$ & 0.50 & $\mathrm{x}$ & 0.85 & 0.52 & $\mathrm{X}$ & $\mathrm{X}$ & 0.38 & 2 \\
\hline & $U_{3}$ & 0.72 & 0.67 & $\mathrm{x}$ & 0.60 & $\mathrm{x}$ & 0.65 & $\mathrm{x}$ & 1 \\
\hline & $U_{4}$ & 0.25 & 0.34 & 0.13 & $\mathrm{x}$ & 0.15 & $\mathrm{X}$ & $x$ & 4 \\
\hline
\end{tabular}

\section{Conclusions}

The proposed method has the following advantages: Weight compensation becomes part of the automatic evaluation process. The scoring rules, including the weight compensation formulas, can be published in advance (RFP) to fulfill the principles of transparency, non-discrimination and equal treatment required by the public sector. The assigned weights of the evaluation criteria are automatically adjusted in relation to the dispersion of values for every criterion in the proposals, avoiding the loss of resolution and the possible selection of a non-optimal solution that are present in the classic approach. The modification of weights in accordance to the dispersion of the values may reduce the risk of rank reversal. The application of the selected linear formulas give a higher resolution: for a given criterion, the highest value is assigned to the best option and the lowest to the worst. The convergence of different types of evaluation in trapezoidal fuzzy numbers, their integration by the arithmetic mean of trapezoids, and defuzzification by the centroid function permit the integration of quantitative and qualitative criteria and provide a more flexible way of evaluation that facilitates the evaluation task. The decomposition of the evaluation factors in a hierarchy with groups of no more than four evaluation criteria facilitates the assignation of weights. 
Nevertheless, the following drawbacks were detected: The segmentation of the evaluation criteria in groups of four factors can lead to artificial classifications that may hinder the assignation of weights. To avoid this problem, weights can also be calculated using AHP. ${ }^{[37]}$ According to Stilger, ${ }^{[38]}$ linear formulas that normalize the values may be subject to rank reversal.

The use of other different formulas and their performance should be investigated. It should be investigated the possible integration of the procedure included in the method proposed by Chen, Yang and $\mathrm{Fan}^{[6]}$ for the compensation of weights in every option to emphasize offers with more balanced criteria. In that case, there would be two weight compensations: The one proposed in this paper that incentivizes significant criteria, and another that compensates criteria within each option, to punish unbalanced offers.

\section{References}

[1] Falagario, M., Sciancalepore, F., Costantino, N., Pietroforte, R. Using a DEA-cross efficiency approach in public procurement tenders. European Journal of Operational Research. 2012; 218(2): 523-529. http://dx.doi.org/10.1016/j.ejor.2011.10.031

[2] European Union. Directive 2004/18/EC of the European parliament and of the council of 31 march 2004 on the coordination of procedures for the award of public works contracts, public supply contracts and public service contracts. Official Journal, L 134, 30.04 2004; 114-240.

[3] Mateus, R., Ferreira, J. A., Carreira, J. Full disclosure of tender evaluation models: Background and application in Portuguese public procurement. Journal of Purchasing and Supply Management. 2010; 16(3): 206-215. http://dx.doi.org/10.1016/j.pursu p. 2010.04.001

[4] Bergman, M. A., Lundberg, S. Tender evaluation and supplier selection methods in public procurement. Journal of Purchasing and Supply Management. 2013; 19(2): 73-83. http://dx.doi.org/1 $0.1016 / j$.pursup. 2013.02.003

[5] Li, H. X., Li, L. X., Wang, J. Y., Mo, Z. W., Li, Y. D. Fuzzy decision making based on variable weights. Mathematical and computer Modelling. 2004; 39(2): 163-179. http://dx.doi.org/10.1016 /S0895-7177(04) 90005-2

[6] Chen, Y., Yang, B.C., Fan, Y. A Decision Making Model of Bid Evaluation Based on Variable Weights-TOPSIS, 2013. http://18 08662.103. sqnet. cn/uploads/soft/130225/GJ31. doc

[7] Li, D. Q., Li, H. X. Analysis of variable weights effect and selection of appropriate state variable weights vector in decision making. Control and Decision. 2004; 11: 1241-1245.

[8] Li, D. Q., Hao, F. L. Weights Transferring Effect of State Variable Weight Vector. Systems Engineering-Theory and Practice. 2009; 29(6): 127-131. http://dx.doi.org/10.1016/S1874-8 $651(10) 60054-3$

[9] Zadeh, L. A. Fuzzy sets. Information and control. 1965; 8(3): 338-353. http://www-bisc.cs.berkeley.edu/zadeh/ papers/Fuzzy\%20Sets-1965.pdf

[10] Vicente, E., Mateos, A., Jiménez, A. A New Similarity Function for Generalized Trapezoidal Fuzzy Numbers. Artificial Intelligence and Soft Computing. 2013; 7894: 400-411.

[11] Kaufmann, A., Gupta, M. M. Fuzzy mathematical models in engineering and management science. Amsterdam, Netherlands: Elseiver Science Publishers. 1988

[12] Kumar, A., Singh, P., Kaur, P., Kaur, A. A new approach for ranking of $\mathrm{L}-\mathrm{R}$ type generalized fuzzy numbers. Expert Systems with Applications. 2011; 38(9): 10906-10910. http://dx.doi.org/1 $0.1016 / j$.eswa. 2011.02 .131

[13] Wang, Y. M. Centroid defuzzification and the maximizing set and minimizing set ranking based on alpha level sets. Computers and Industrial Engineering. 2009; 57(1): 228-236. http://dx.doi.org $/ 10.1016 / j$.cie. 2008.11.014

[14] Wang, Y. M., Luo, Y. On rank reversal in decision analysis. Mathematical and Computer Modelling. 2009; 49 (5): 1221-1229.
[15] Shipley, M. F., Stading, G. L., Davis, J. A Fuzzy Set Based Evaluation of Suppliers on Delivery, Front Office Quality and Value-Added Services. Information Processing and Management of Uncertainty in Knowledge-Based Systems. Computer and Information Science. 2014; 442: 355-365. http://dx.doi.org/10.1007/978-3-319 $-08795-5 \_37$

[16] Rodríguez, A., Ortega, F., Concepción, R. A method for the selection of customized equipment suppliers. Expert Systems with Applications. 2013; 40 (4): 1170-1176. http://dx.doi.org/10.10 $16 / j$.eswa. 2012.08 .021

[17] Khamseh, A. A. Mahmoodi, M. A. New Fuzzy TOPSIS-TODIM Hybrid Method for Green Supplier Selection Using Fuzzy Time Function. Advances in Fuzzy Systems. 2014. http://dx.doi.o $\mathrm{rg} / 10.1155 / 2014 / 841405$

[18] Chen, C. T., Lin, C. T., Huang, S. F. A fuzzy approach for supplier evaluation and selection in supply chain management. International Journal of Production Economics. 2006; 102(2): 289-301. http://dx.doi.org/10.1016/j.ijpe.2005.03.009

[19] Guneri, A. F., Yucel, A., Ayyildiz, G. An integrated fuzzy-lp approach for a supplier selection problem in supply chain management. Expert Systems with Applications. 2009; 36(5): 9223-9228. http://dx.doi.org/10.1016/j.eswa.2008.12.021

[20] Wang, J. W., Cheng, C. H., Huang, K. C. Fuzzy hierarchical TOPSIS for supplier selection. Applied Soft Computing. 2009; 9(1): 377386. http://dx.doi.org/10.1016/j.asoc.2008.04.014

[21] Sanayei, A., Farid Mousavi, S., Yazdankhah, A. Group decision making process for supplier selection with VIKOR under fuzzy environment. Expert Systems with Applications. 2010; 37(1): 24-30. http://dx.doi.org/10.1016/j.eswa.2009.04.063

[22] Liao, C. N., Kao, H. P. An integrated fuzzy TOPSIS and MCGP approach to supplier selection in supply chain management. Expert Systems with Applications. 2011; 38(9): 10803-10811. http: //dx.doi.org/10.1016/10.1016/j.eswa.2011.02.031

[23] Luukka, P. Fuzzy similarity in multicriteria decision-making problem applied to supplier evaluation and selection in supply chain management. Advances in Artificial Intelligence. 2011; (6).

[24] Amindoust, A., Ahmed, S., Saghafinia, A., and Bahreininejad, A. Sustainable supplier selection: A ranking model based on fuzzy inference system. Applied Soft Computing. 2012; 12(6): 1668-1677. http://dx.doi.org/10.1016/j.asoc.2012.01.023

[25] Ferreira, L., Borenstein, D. A fuzzy-Bayesian model for supplier selection. Expert Systems with Applications. 2012; 39(9): 7834-7844. http://dx.doi.org/10.1016/j.eswa.2012.01.068

[26] Pattnaik, M. Fuzzy Supplier Selection Strategies in Supply Chain Management. International Journal of Supply Chain Management. 2013; 2(1). http://ojs.excelingtech.co.uk/index.php/I JSCM/article/view/719/389

[27] Sehra, S. K., Brar, Y. S., Kaur, N. Multi-Criteria Decision Making Approach for Selecting Effort Estimation Model. International Journal of Computer Applications. 2012; 39(1). http://dx.doi.org /10.5120/4783-6989

[28] Xie, H., Shi, L., Xu, H. Transformer Maintenance Policies Selection Based on an Improved Fuzzy Analytic Hierarchy Process. Journal of 
Computers. 2013; 8(5): 1343-1350. http://dx.doi.org/10.43 $04 / j \mathrm{jcp} .8 .5 \cdot 1343-1350$

[29] Dini, F., Pacini, R., Valletti, T. Scoring rules. Handbook of Procurement, Chapter 12. 293, 321. Cambridge University Press. 2006.

[30] Liang, Z., Wang, Y., Ren, Y., Li, D., Voss, L., Sleigh, J., et al. Detection of Burst Suppression Patterns in EEG Using Recurrence Rate. The Scientific World Journal. 2014. http://dx.doi.org/10.11 55/2014/295070

[31] Zeng, J., An, M., Smith, N. J. Application of a fuzzy based decision making methodology to construction project risk assessment. International journal of project management. 2007; 25(6): 589-600. http://dx.doi.org/10.1016/j.ijproman.2007.02.006

[32] Pandey, M., Khare, N., Shrivastava, S. C. New Aggregation Operator for Trapezoidal Fuzzy Numbers based on the Arithmetic Means of the Left and Right Apex Angles. International Journal of Advanced Research in Computer Science and Software Engineering. 2012; 2(3): 430, 433.

[33] Yang, T., Hsieh, C. H. Six-Sigma project selection using national quality award criteria and Delphi fuzzy multiple criteria decision-making method. Expert Systems with Applications. 2009; 36(4): 7594-7603. http://dx.doi.org/10.1016/j.eswa. 20 08.09 .045
[34] Bichler, M., Kalagnanam, J. Configurable offers and winner determination in multi-attribute auctions. European Journal of Operational Research. 2005; 160(2): 380-394. http://dx.doi.org/1 $0.1016 / j . e j$ or. 2003.07 .014

[35] Liu, B., Zhang, X., Xie, S., Ma, H. Variable Weights DecisionMaking and Its Fuzzy Inference Implementation. Fourth International Conference on Fuzzy Systems and Knowledge Discovery, August 2007. IEEE. FSKD. 2007; 2: 635-640. http://dx.doi.org /10.1109/FSKD. 2007.607

[36] Subin, W. E. N. The Variable Weights Evaluation Model of the Triple Performance of Enterprise based on Sustainable Development. 2007. http://www. seiofbluemountain.com/upload/p roduct/200910/2008glhy02a3.pdf

[37] Ishizaka, A., Labib, A. Review of the main developments in the analytic hierarchy process. Expert Systems with Applications. 2011; 38(11): 14336-14345. http://dx.doi.org/10.1016/j.eswa. 2011.04 .143

[38] Stilger, P. S. Formulas for Choosing the Most Economically Advantageous Tender-a Comparative Study (Part 1). Master Thesis. Utrecht University, Faculty of Science. 2011. http://igitur-archive.library .uu.nl/student-these s/2012-0327-200536/StilgerPSMA2011Part\%20I.pdf 